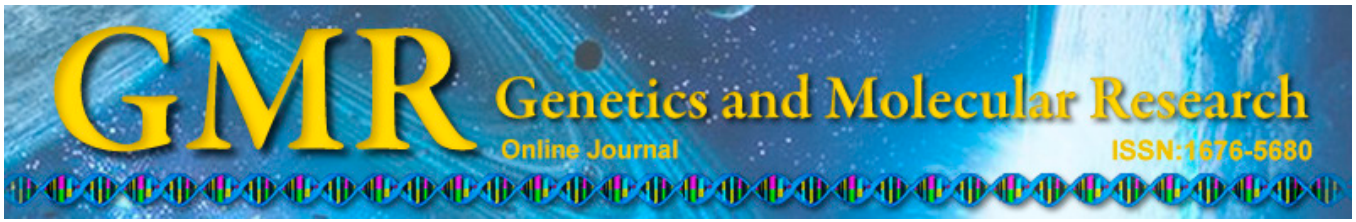

\title{
Effect of human umbilical cord mesenchymal stem cells on endometriotic cell proliferation and apoptosis
}

\author{
L.N. Xü ${ }^{1 *}$ N. Lin ${ }^{2 *}$, B.N. Xü ${ }^{3}$ J.B. Li ${ }^{1}$ and S.Q. Chen ${ }^{1}$ \\ ${ }^{1}$ Department of Gynecology and Obstetrics, \\ The First Affiliated Hospital of Sun Yat-sen University, \\ Guangzhou, Guangdong Province, China \\ ${ }^{2}$ Department of Surgery, The Third Affiliated Hospital of Sun Yat-sen University, \\ Guangzhou, Guangdong Province, China \\ ${ }^{3}$ Department of Gynecology and Obstetrics, \\ The First People's Hospital of Foshan, Foshan, Guangdong Province, China
}

*These authors contributed equally to this study.

Corresponding author: S.Q. Chen

E-mail: sqdoccn@yeah.net

Genet. Mol. Res. 14 (4): 16553-16561 (2015)

Received August 7, 2015

Accepted October 8, 2015

Published December 11, 2015

DOI http://dx.doi.org/10.4238/2015.December. 11.2

\begin{abstract}
The objective of this study was to observe the effects of human umbilical cord mesenchymal stem cells (UCMSCs) on the proliferation and apoptosis of endometriotic cells. Endometriotic cells and UCMSCs were primarily cultured in vitro. In the experimental group, a UCMSC and endometriotic cell non-contact co-culture system was established. The control group consisted of $1 \times 10^{5}$ endometriotic cells cultured alone. The proliferation and apoptosis of endometriotic cells were respectively detected using the MTT method and flow
\end{abstract}


cytometry. The mRNA expression level of the tensin homologue gene $(P T E N)$ in endometriotic cells was detected by reverse transcriptionpolymerase chain reaction amplification. Compared with the control group, the proliferation of endometriotic cells in the experimental group was clearly inhibited $(\mathrm{P}<0.05)$ and time-dependent $(\mathrm{P}<0.05)$. In addition, the number of apoptotic cells were significantly increased ( $\mathrm{P}$ $<0.05)$, and the amount of cells, which entered S phase from G1 phase, decreased significantly. Furthermore, the mRNA expression level of the PTEN gene in the experimental group was significantly higher than in the control group $(\mathrm{P}<0.05)$. These results suggest that UCMSCs might inhibit the proliferation of human endometriotic cells in vitro and promote their apoptosis by upregulating the expression of PTEN.

Key words: Human umbilical cord mesenchymal stem cells; Apoptosis; Endometriotic cells; Co-culture; Tensin homologue gene

\section{INTRODUCTION}

Endometriosis (EMS) is a common benign gynecological disease. Its primary clinical manifestations are dysmenorrhea and infertility. Endometriosis often occurs in women of childbearing age, in whom its incidence rate is approximately 10 to $20 \%$ and shows an increasing trend. Therefore, endometriosis seriously affects the physical and mental as well as reproductive health of women of childbearing age (van der Linden, 1996). The etiology and pathogenesis of EMS are not yet clear. Gonadotropin-releasing hormone agonist (GnRH-A) is widely recognized as the most effective current treatment. However, the recurrence rate of EMS is extremely high after drug withdrawal and estrogen-related side effects may occur at low frequency (Bulun, 2009). In addition, although EMS is a benign disease, it has biological behaviors, which are similar to the behaviors of malignant tumors, such as angiogenesis and local and distant metastasis (Swiersz, 2002; Wu and Ho, 2003).

$P T E N$ is also a major negative regulator of the PI3K/AKt signaling pathway. Currently, it is believed that PTEN is one of the important housekeeping genes in endometrial tissue. PTEN gene expression changes in a variety of endometrial lesions (Harada et al., 2004). Some research results have shown that the mRNA expression level of the PTEN gene is closely correlated with the occurrence and severity of EMS, and mRNA expression levels of the PTEN gene have been shown to rise after EMS drug treatment (Dinulescu et al., 2005; Xu et al., 2011).

Human umbilical cord mesenchymal stem cells (UCMSCs) are a kind of pluripotent stem cells derived from the mesoderm and a type of adult mesenchymal stem cells. They have the potential of self-renewal and of multi-directional differentiation. Research indicates that UCMSCs can upregulate the expression of PTEN, which leads to the decline of the migration ability of tumor cells and thus inhibits their biological activity (Ali, 2000). This mechanism is also supported by our research members' findings, that is, that UCMSCs induce the apoptosis of hepatic stellate cells by upregulating the expression of PTEN (Long et al., 2013).

Therefore, in this study, the proliferation and apoptosis of endometriotic cells and the expression level of PTEN in cells were detected following co-culture of UCMSCs and endometriotic cells to preliminarily investigate whether UCMSCs regulate the proliferation and apoptosis of endometriotic cells by upregulating the PTEN gene in vitro. 


\section{MATERIAL AND METHODS}

\section{Subjects}

From June 2009 to August 2011, 35 patients with endometriosis were admitted to the Department of Gynecology in the First Affiliated Hospital of Sun Yat-sen University. All patients signed an informed consent and were diagnosed by postoperative pathologic examination. Patients were aged from 31 to 46 years, with the average age of $33.1 \pm 2.8$ years. During surgery, a typical ectopic focus was selected under sterile conditions for endometriotic cell culture. Meanwhile, umbilical cords of healthy patients undergoing Cesarean delivery in the Obstetrical Department in our hospital were collected under sterile conditions for primary culture of UCMSCs.

\section{Methods}

\section{Isolation and culture of primary endometriotic cells}

The isolation and culture methods of primary endometriotic cells were as previously reported (Xiao et al., 2002): Endometriotic tissues of patients were collected under sterile conditions and then cut up to reach a particle volume of approximately $1 \mathrm{~mm}^{3}$. To this, $0.1 \%$ type IV collagenase was added to digest the samples for 3.0 to $4.0 \mathrm{~h}$. Cells were resuspended and counted, then inoculated at the concentration of $10^{9}$ cells $/ \mathrm{L}$ in a $25-\mathrm{cm}^{2}$ culture flask to which 4.0 to $5.0 \mathrm{~mL}$ high glucose Dulbecco's modified Eagle's medium (DMEM, Gibco Co., USA) containing 10\% volume fraction fetal bovine serum (FBS, Hyclone Co., USA), $10 \mathrm{~g} / \mathrm{L}$ insulin, and a working concentration of double-antibody $(0.1 \mathrm{U} / \mu \mathrm{L})$ was added. The cells were cultured in a 0.05 volume fraction of $\mathrm{CO}_{2}$ incubator at $37^{\circ} \mathrm{C}$. Two days later, the medium was changed and non-adherent cells were removed. Two or three days after this, the medium was changed. Cell growth was observed under an inverted microscope.

\section{Isolation and culture of UCMSCs}

A 5-cm section of healthy umbilical cord was collected under sterile conditions and then washed with phosphate-buffered saline (PBS). The umbilical cord outer membrane and vessels were isolated and removed. The remaining tissues were cut into small blocks whose volume was $10 \mathrm{~mm}^{3}$. The blocks were added into separating medium (DMEM/F12, 10\% volume fraction of FBS, $0.1 \%$ collagenase I, and $0.1 \%$ hyaluronidase) to digest in a 0.05 volume fraction $\mathrm{CO}_{2}$ humidified incubator at $37^{\circ} \mathrm{C}$ overnight. Filtrate containing cells was collected through a 100 -mesh sieve, and centrifuged at $1000 \mathrm{rpm}$ for $10 \mathrm{~min}$ at ambient temperature. The supernatant was removed. The pelleted cells were resuspended and cultured in DMEM/ F12 medium containing 10\% volume fraction FBS and double-antibody (penicillin and streptomycin, both concentrations $100 \mathrm{U} / \mathrm{mL}$ ). Cells were cultured in a 0.05 volume fraction $\mathrm{CO}_{2}$ humidified incubator at $37^{\circ} \mathrm{C}$. Three days later, all of the medium was replaced for the first time. UCMSCs were obtained by the differential adherence method. Cell phenotypes (1:100, presence of CD34, CD45, CD54, and CD90: Boster Ltd., Wuhai, China) of the third and fourth generation of cultured cells were detected respectively by flow cytometry (BD FACSCalibur, BD Co., USA). If umbilical cord-derived mesenchymal stem cells were positive for mesenchymal makers (CD34, CD45, CD54, CD90), the cells were identified to be UCMSCs by flow 
cytometry. Then, they would be used in further experiments.

\section{Establishment of an indirect co-culture system of UCMSCs and endometrial cells}

Endometrial cells and UCMSCs were respectively inoculated into the upper and lower wells of Transwell co-culture plates (Corning Co., USA) to establish the double-deck non-contact co-culture system. The ratio and total number of endometrial cells to UCMSCs was $1 \times 10^{5}$ : $1 \times 10^{5}$. In addition, endometrial cells $\left(1 \times 10^{5}\right)$ were cultured alone to serve as the control group.

\section{Proliferation of endometrial cells}

Cell proliferation was detected by MTT. Endometrial cells cultured at different time points $(24,48$, and $72 \mathrm{~h})$ in experimental and control groups were digested and inoculated onto 96-well culture plates at the concentration of $1 \times 10^{8}$ cells/L. MTT $(20 \mu \mathrm{L} ; 5 \mathrm{~g} / \mathrm{L})$ was added to each well. The cells were cultured in an incubator for $4 \mathrm{~h}$. The medium was removed and $150 \mu \mathrm{L}$ dimethyl sulfoxide (DMSO) was added to each well. Sufficient oscillation was carried out to dissolve the crystals. The number of proliferative cells was detected by an enzyme-linked detector (Nanjing Huadong Electronic Appliance Co., Ltd., Nanjing, China) at a wavelength of $570 \mathrm{~nm}$. Three repeated wells were set for each sample and blank wells were set as controls. All experiments were repeated three times and the mean value was used. Excel 2007 (Microsoft Corp., Redmond, WA, USA) was used for drawing.

\section{Detection of cell cycle stage and apoptosis rate by flow cytometry}

Cells co-cultured for 24, 48, and $72 \mathrm{~h}$ were digested to obtain endometrial cells. Endometrial cells were washed with PBS three times and then suspended and fixed with $70 \%$ volume fraction precooled ethanol. The cells were stored at $4{ }^{\circ} \mathrm{C}$ overnight and then washed twice with an equal quantity of PBS. Subsequently, $100 \mu \mathrm{L}$ RNase A was added and the mixture was heated in a water bath at $37^{\circ} \mathrm{C}$ for $30 \mathrm{~min}$. Polyimide (PI single staining method) developing was carried out without light at $4^{\circ} \mathrm{C}$ for $30 \mathrm{~min}$. The percentages of necrotic, apoptotic, and normal cells were detected by flow cytometry. ModFit (Verity Software House Co., USA) was used for the analysis of cell cycle.

\section{Extraction of total RNA from endometriotic cells}

Endometriotic cells co-cultured for 24, 48, and $72 \mathrm{~h}$ were respectively collected and the media of the culture plates were removed. The cells were washed once with PBS, then, 1 mL RNAiso Plus (BD Biosciences, San Jose, CA, USA) was added to each well. When the cell layer was submerged, the cells were gently blown to facilitate shedding. The cell suspension was transferred to an Eppendorf (EP) tube, and left to stand for $5 \mathrm{~min}$ at ambient temperature. Subsequently, $200 \mu \mathrm{L}$ chloroform was added to the EP tube and mixed uniformly by shaking. After standing for an additional $5 \mathrm{~min}$, the mixture was centrifuged at $12,000 \mathrm{~g}$ for $15 \mathrm{~min}$ at $4^{\circ} \mathrm{C}$. The centrifuge tube was taken out carefully. At that time, the homogenate was divided into three layers. The supernatant in the top layer was pipetted off and transferred to a new EP tube, followed by addition of $500 \mu \mathrm{L}$ propofol (RNAiso Plus reagent, BD Biosciences), and the tube was shaken to mix the components uniformly. After standing for $10 \mathrm{~min}$, the tube was 
centrifuged at $12,000 \mathrm{~g}$ for $10 \mathrm{~min}$ at $4^{\circ} \mathrm{C}$. The supernatant was removed carefully, and the tube wall was washed with $1 \mathrm{~mL} \mathrm{70 \%} \mathrm{volume} \mathrm{fraction} \mathrm{ethanol,} \mathrm{followed} \mathrm{by} \mathrm{centrifugation} \mathrm{at}$ $12,000 \mathrm{~g}$ for $5 \mathrm{~min}$ at $4^{\circ} \mathrm{C}$. The precipitate was dried for $5 \mathrm{~min}$ at ambient temperature and then dissolved with $40 \mu \mathrm{L}$ RNase-free water. The solution was stored at $-80^{\circ} \mathrm{C}$. All experiments were repeated three times.

\section{Detection of PTEN mRNA expression by reverse transcription-polymerase chain reaction (RT-PCR) amplification}

Total RNA was reverse transcribed to $20 \mu \mathrm{L}$ cDNA by PCR according to kit specifications. The reaction system consisted of $2 \mu \mathrm{L}$ cDNA, $2 \mu \mathrm{L}$ target gene upstream $(0.1 \mathrm{U} / \mu \mathrm{L})$ and $2 \mu \mathrm{L}$ downstream primer $(0.1 \mathrm{U} / \mu \mathrm{L}), 5 \mu \mathrm{L} 2 \mathrm{X} \mathrm{HS}^{\mathrm{TM}}$ Reaction Mix, $0.2 \mu \mathrm{L}$ Taq DNA polymerase $(2.5 \mathrm{U} / \mu \mathrm{L})$, and $8.8 \mu \mathrm{L}$ ultrapure water in a total volume of $20 \mu \mathrm{L}$. All operations were carried out on ice. The established reaction system was transferred to a PCR instrument for amplification (ABI 7500 Automatic Fluorescent Quantitative PCR Instrument, ABI Co., USA) using the following conditions: $94^{\circ} \mathrm{C}$ for $3 \mathrm{~min} ; 94^{\circ} \mathrm{C}$ for $30 \mathrm{~s}, 60^{\circ} \mathrm{C}$ for $30 \mathrm{~s}$ and $72^{\circ} \mathrm{C}$ for $1 \mathrm{~min}$, 30 cycles; $72^{\circ} \mathrm{C}$ for $10 \mathrm{~min}$. After amplification, $5 \mu \mathrm{L}$ solution was used for $1 \%$ agarose gel electrophoresis. Primers were designed according to the literature (Obata and Hoshiai, 2000).

\section{Statistical analysis}

Data are reported as means \pm standard deviation. SPSS 13.0 (SPSS, Chicago, IL, USA) was used for statistical analysis. The $t$-test was used for comparisons between groups. P $<0.05$ was accepted as statistically significant.

\section{RESULTS}

\section{Morphological observation of UCMSCs}

Under an inverted microscope, it was observed that UCMSCs showed the shuttle-like morphology of fibroblasts. The cell volume was uniform. Meanwhile, a swirl colony growth form was represented. The transparency of the single cells was good (Figure 1).

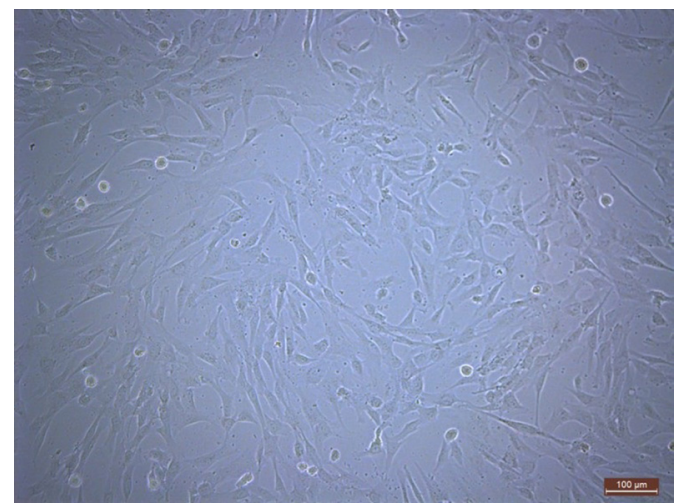

Figure 1. Human umbilical cord mesenchymal stem cells under inverted microscope (5X). 
Surface molecules of UCMSCs were detected by flow cytometry, which suggested that UCMSCs expressed CD54 and CD90 rather than CD34 and CD45; CD34 and CD45 are specific markers of hematopoietic cell surfaces.

\section{Morphological signs of endometriotic cells}

Under an inverted microscope, it was observed that cultured glandular epithelial cells had a small size, clear cell outlines, and large and clear nuclei. The cells grew in groups.

\section{Detection of endometriotic cell proliferation using the MTT method}

Compared with the control group, proliferation of endometriotic cells at different time points in the experimental group was significantly inhibited $(\mathrm{P}<0.05)$. In addition, the differences of cell inhibition ratios between different time points were statistically significant $(72<$ $48<24 \mathrm{~h}, \mathrm{P}<0.05$ ) (Figure 2).

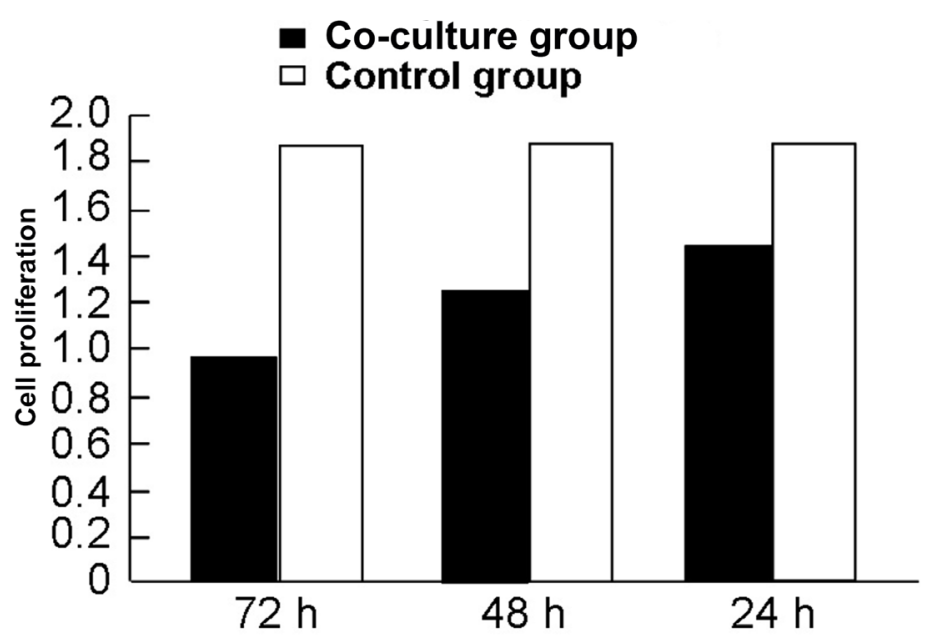

Figure 2. Cell proliferation after co-culture with human umbilical cord mesenchymal stem cells detected by MTT.

\section{Detection of endometriotic cell apoptosis by flow cytometry}

The apoptosis status of endometriotic cells co-cultured with UCMSCs at different time points was detected by flow cytometry, which showed decreased numbers of co-cultured cells in $\mathrm{S}$ phase and an inhibition of cells transitioning from $\mathrm{G} 1$ to $\mathrm{S}$ phase. The proportion of hypodiploid peaks of each co-culture group within the total number of cells is shown in Table 1.

\section{Detection of PTEN gene expression in endometriotic cells by RT-PCR}

Compared with the control group, PTEN gene expression at different time points in the experimental group was clearly upregulated. In the experimental group, compared with cells co-cultured for $24 \mathrm{~h}$, PTEN gene expression in cells co-cultured for 48 and $72 \mathrm{~h}$ were upregulated as well (Figure 3). 
Table 1. Apoptosis of endometrial cells before and after co-culture with human umbilical cord mesenchymal stem cells as detected by flow cytometry (means $\pm \mathrm{SD}, \%$ ).

\begin{tabular}{lcrr}
\hline Group & \multicolumn{3}{c}{ Cell cycle } \\
\cline { 2 - 4 } & G1 stage & S stage & G2/M stage \\
\hline Experimental & & & \\
$24 \mathrm{~h}$ & $80.6 \pm 1.3$ & $15.1 \pm 1.6^{\mathrm{a}}$ & $4.3 \pm 0.5$ \\
$48 \mathrm{~h}$ & $86.1 \pm 1.1$ & $11.2 \pm 1.1^{\mathrm{a}}$ & $2.7 \pm 0.3$ \\
$72 \mathrm{~h}$ & $91.2 \pm 0.9$ & $7.3 \pm 0.8^{\mathrm{a}}$ & $1.5 \pm 0.8$ \\
\hline
\end{tabular}

$24 \mathrm{~h} \quad 48 \mathrm{~h} \quad 72 \mathrm{~h}$

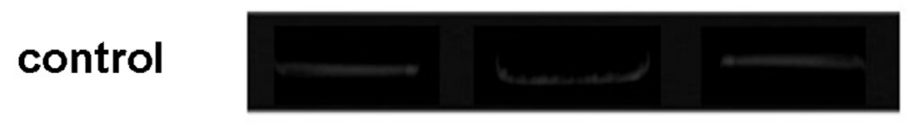

\section{experimental}

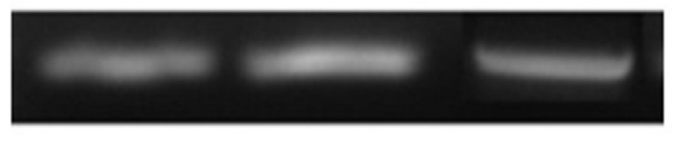

\section{GAPDH}

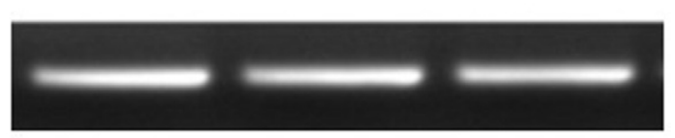

Figure 3. Expression of PTEN mRNA in endometrial cells before and after co-culture with human umbilical cord mesenchymal stem cells.

\section{DISCUSSION}

In the early 20th century, a surgeon named Cullen reported a form of endometriosis, which had a growth capability and appeared outside the part of the uterine cavity coated with mucosa. That was the first time that endometriosis was defined clinically (Cullen, 1908). Its pathogenesis is varied, involving blood reflux, endometrial dysfunction, hormone, immune, heredity, and peritoneal environment, etc. However, there is currently no theory that can clarify the pathogenesis of endometriosis (Brosens and Benagiano, 2011). As a special tissue of human body, endometrial tissue has a continuous physiological process of proliferation, secretion changes, and necrosis. Research has shown that the occurrence of endometriosis is related to the effective apoptosis of endometriotic cells during the menstrual period. In 1976, Hopwood and Levison (1976) proposed for the first time that there is considerable loss of gland epithelial cells with formation of apoptotic bodies in the late secretory, premenstrual and menstrual phases of human cyclical endometrium, but also to a lesser extent in the proliferative phase. Apoptotic bodies containing nuclear fragments may be recognised on light microscopy as basophilic or Feulgen positive granules. Recently, an increasing number of studies have demonstrated that apoptosis plays an important role in women by eliminating endometriotic cells and maintaining the stability of the intracellular environment during the menstrual cycle (Taniguchi et al., 2011). The occurrence of endometriosis is obviously related 
to the occurrence and changes of the apoptotic characteristics of endometriotic cells. Gebel et al. (1998) proposed that the apoptosis function of endometrial tissue would be damaged after ectopic implantation of endometriosis. Harada et al. (2004) compared the apoptosis sensitivities of eutopic and ectopic endometrial tissues of patients with endometriosis with those of normal endometrial tissue and found that the apoptosis sensitivities of both eutopic and ectopic endometrial tissues of patients with endometriosis were decreased, especially those of the ectopic endometrial tissue. Cibula et al. (2003) found that anti-apoptosis characteristics of cell tissue were not affected by disease stages and severity of symptoms in patients with peritoneal endometriosis of different stages and severities.

Deletion of the phosphatase and tensin homolog PTEN on chromosome 10 has recently been found (Ali, 2000). Expression of the PTEN gene was found to be changed in many diseases related to the endometrium. The PTEN gene has also been proven to be one of the important housekeeping genes in endometrial tissue (Ali, 2000). PTEN is the first tumor suppressor gene shown to have phosphatase activity. It is located in human chromosome 10q23.3. Its sequence contains an open reading frame of 1212 oligonucleotides encoding a protein of 403 amino acids. The upregulation of PTEN gene expression can significantly inhibit cell proliferation. Through its substrate specific phosphatase characteristic, PTEN plays the role of tumor suppressor gene via PI3K, MAPK, and other signaling pathways, which causes cells to stagnate during the transition from $\mathrm{G} 0 / \mathrm{G} 1$ to $\mathrm{S}$ phase and thereby induces the retention of cells in G1 phase and promotes their apoptosis (Weng et al., 1999; Cheung et al., 2004). Some scholars have compared the expression of PTEN mRNA in endometrial tissues of patients with endometriosis and of normal women and have found that the mRNA expression levels of PTEN are closely correlated with the occurrence and clinical severity of endometriosis. In addition, the mRNA expression of PTEN also rises following the treatment of endometriosis with drugs (Dinulescu et al., 2005; Xu et al., 2011).

UCMSCs are a kind of recently identified pluripotent stem cell derived from the mesoderm. They belong to the category of adult stem cells. UCMSCs have the potential of selfrenewal and of multi-directional differentiation. UCMSCs are excellent seed cells for tissue engineering. Related studies have found that mesenchymal stem cells can induce the apoptosis of hepatic stellate cells through paracrine function (Lin et al., 2009). In the current study, it was found that, after non-contact co-culture of UCMSCs and endometriotic cells, the apoptosis of endometriotic cells was obviously increased compared with the control group. Furthermore, the proliferation of endometriotic cells was inhibited and the mRNA expression of PTEN increased. The experiment demonstrated that the increase of PTEN mRNA expression was accompanied by the apoptosis and proliferation inhibition of endometriotic cells; that is, the improvement of endometriosis characteristics demonstrates that PTEN is a key gene in the occurrence and development of endometriosis. Through paracrine mechanisms, UCMSCs can induce the inhibition of proliferation and an increase in apoptosis of endometriotic cells and cause the rise of PTEN mRNA expression, which might provide certain scientific basis for the treatment of endometriosis with UCMSCs in the future. However, because this experiment is relatively preliminary, specific mechanisms have not been studied in detail and remain to be further studied.

\section{Conflicts of interest}

The authors declare no conflict of interest. 


\section{ACKNOWLEDGMENTS}

Research supported by a grant from the National Natural Science Foundation of China (\#81070472, to S.Q. Chen and \#81272642, to N. Lin), the Science and Techlology Project Planning of Guangdong Province, China (\#2012B031800121, to S.Q. Chen), and the Specialized Research Fund for the Doctoral Program of Higher Education (\#20110171110070, to N. Lin).

\section{REFERENCES}

Ali IU (2000). Gatekeeper for endometrium: The PTEN tumor suppressor gene. J. Natl. Cancer Inst. 92: 861-863.

Brosens I and Benagiano G (2011). Endometriosis, a modern syndrome. Indian J. Med. Res. 133: 581-593.

Bulun SE (2009). Endometriosis. N. Eng. J. Med. 360: 268-279.

Cheung TH, Lo KW, Yim SF, Chan LK, et al. (2004). Epigenetic and genetic alternation of PTEN in cervical neoplasm. Gynecol. Oncol. 93: 621-627.

Cibula D, Hach P, Kucera T, Kuzel D, et al. (2003). The role apoptosis in the extent of endometriosis and its clinical symptomatology. Ceska Gynekol. 68: 59-63.

Cullen TS (1908). Adenomyoma of the uterus. W.B. Saunders Co., Philadelphia.

Dinulescu DM, Ince TA, Quade BJ, Shafer SA, et al. (2005). Role of K-ras and Pten in the development of mouse models of endometriosis and endometrioid ovarian cancer. Nat. Med. 11: 63-70.

Gebel HM, Braun DP, Tambur A, Frame D, et al. (1998). Spontaneous apoptosis of endometrial tissue is impaired in women with endometriosis. Fertil. Steril. 69: 1042-1047.

Harada T, Kaponis A, Iwabe T, Taniguchi F, et al. (2004). Apoptosis in human endometrium and endometriosis. Hum. Reprod. Update 10: 29-38.

Hopwood D and Levison DA (1976). Atrophy and apoptosis in the cyclical human endometrium. J. Pathol. 119:159-166.

Lin N, Hu K, Chen S, Xie S, et al. (2009). Nerve growth factor-mediated paracrine regulation of hepatic stellate cells by multipotent mesenchymal stromal cells. Life Sci. 85: 291-295.

Long SH, He Y, Chen MH, et al. (2013). Activation of PI3K/Akt/mTOR signaling pathway triggered by PTEN downregulation in the pathogenesis of Crohn's disease. J . Dig. Dis. 14: 662-669.

Mutter GL, Lin MC, Fitzgerald JT, Kum JB, et al. (2000). Changes in endometrial PTEN expression throughout the human menstrual cycle. J. Clin. Endocrinol. Metab. 85: 2334-2338.

Obata K and Hoshiai H (2000). Common genetic changes between endometriosis and ovarian cancer. Gynecol. Obstet. Invest. 50: 39-43.

Swiersz LM (2002). Role of endometriosis in cancer and tumor development. Ann. N. Y. Acad. Sci. 955: 281-292.

Taniguchi F, Kaponis A, Izawa M, Kiyama T, et al. (2011). Apoptosis and endometriosis. Front. Biosci. 3: 648-662.

van der Linden PJ (1996). Theories on the pathogenesis of endometriosis. Hum. Reprod. 11: 53-56.

Weng LP, Smith WM, Dahia PL, Ziebold U, et al. (1999). PTEN suppresses breast cancer cell growth by phosphatase activity dependent G1 arrest followed by cell death. Cancer Res. 59: 5808-5814.

Wu MY and Ho HN (2003). The role of cytokines in endometriosis. Am. J. Reprod. Immunol. 49: 285-296.

Xiao YH, Chen DP, Yan JH and Yokoyama Y (2002). Mechanism of action of Tripterygium wilfordii polyglycoside on experimental endometriosis. Eur. J. Gynaecol. Oncol. 23: 63-67.

Xu B, Hamada S, Kusuki I, Itoh R, et al. (2011). Possible involvement of loss of heterozygosity in malignant transformation of ovarian endometriosis. Gynecol. Oncol. 120: 239-246. 